\title{
Acceptance of Feedbacks in Reputation Systems: The Role of Online Social Interactions
}

\author{
${ }^{*}$ Fereshteh Ghazizadeh Ehsaei, Ab. Razak Che Hussin \\ University Technology Malaysia (UTM), Johor, Malaysia \\ *Fgh139@gmail.com
}

\begin{abstract}
In an online environment, the aim of reputation systems is to let parties rate each other and to help consumers in deciding whether to transact with a given party. In current reputation systems for e-commerce, users have to trust unreliable information sources and anonymous people. As a result, users are not only hesitant to trust online seller but also to reputation systems. Therefore, there is a need to improve current reputation systems by allowing users to make buying decision based on reliable source of information. This paper proposes a new approach of sharing knowledge and experience in reputation systems by utilizing social interactions. This study examines the potentials of integrating social relations information in reputation systems by proposing a model of acceptance of feedbacks in reputation systems.
\end{abstract}

Keywords: E-commerce, Trust, Reputation Systems, Social Networks, Online

\section{Introduction}

In e-commerce environment, as physical presence of participants is not provided, there is uncertainty regarding the reliability of products, services and providers. Therefore, making decision on whom to trust and which transaction to engage becomes difficult. Reputation systems are one of the established mechanisms to assist consumers in making decision in online shopping (Gutowska \& Sloane, 2010). Reputation systems help people to distinguish trustworthy parties and influence buyers that may base their buying decision on the past history (Resnick, Zeckhauser, Friedman, \& Kuwabara, 2000). For example, a growing number of e-commerce sites such as Amazon.com display evaluations by consumers in order to offer other consumers reliable products or services on their sites. Research on reputation systems has shown that these systems can potentially play an important role in e-commerce as a trust building mechanism being used by consumers and as an effective tool for marketing purposes for e-sellers (Gregg \& Scott, 2006). Although the trend for reputation system is growing, they still face many challenges. As feedbacks are submitted via an unlimited number of unknown participants and the information in most reputation systems are unfiltered, this makes the information validity uncertain. For example, unreliable users can assign incorrect or poor information from. Hence there is a need for enhancement of feedbacks in reputation systems; these mechanisms should involve measuring the trustworthiness of feedbacks in the systems and the effectiveness of the systems in the process of decision making for online shopping (Komiak, 2010). As a solution on these problems, in a research we study peoples' willingness to accept the feedbacks in reputation systems, and it would help to better understand the process by which feedbacks are being used in consumer's decision-making. In this study, we investigate the effect of additional relationship information to enhance the acceptance of feedbacks in reputations system. This paper is organized as follows: In section 2 , we first present literature on trust and reputation. Thereafter we will present the challenges that current reputation systems are involved. Then we will describe the potential of using social relations information in reputation system. In section 3, we discuss the proposed research model including identifying the relevant factors and explain each construct. In section 4, we present the future work and finally conclusion is discussed.

\section{Literature Review}

Trust and Reputation: The concept of reputation is closely linked to that of trustworthiness. At a general level trust can be described as a willingness of a party to be vulnerable to actions of another party based on the expectations that the other will perform a particular action important to the trustee, irrespective of the ability to monitor or control that other party (Mayer, Davis, \& Schoorman, 1995). The reputation is generally said or believed to be about a person's or things' character or standing (Jøsang, Ismail, \& Boyd, 2007). 
Reputation can be considered as a collective measure of trustworthiness based on the referrals of ratings from members in a community. The effect of reputation information on trust formation has been illustrated in a variety of settings and in different streams of research (Ba \& Pavlou, 2002; Fuller, Serva, \& Benamati, 2007; Zucker, 1986). Studies have shown that reputation, generally characterized as information, represent a publicly help perception of a specific referent. Reputation information may be most critical, particularly, when the consumer has little direct knowledge or experience with a particular vendor (Zucker, 1986). Determining that an e-seller has a favorable reputation can reduce consumer concerns regarding a purchase, increase consumer trust and commitment toward the company, and encourage online purchasing ( $\mathrm{Li}$, Browne, \& Chau, 2006; McDonald \& Slawson Jr., 2002; Resnick, et al., 2000). Reputation also provides an indication of what other consumers are doing, which can be a powerful predictor of purchasing behavior. Reputation may be even more crucial in an online environment than a traditional environment. There are two fundamental differences between traditional and online environments on how trust and reputation are and can be used. Firstly, the traditional cues of trust and reputation that people use to observe and depend on in the physical world are missing in online environments, so that the electronic substitutes are needed (Resnick, et al., 2000). Secondly, communicating and sharing information related to trust and reputation is relatively difficult and normally constrained to local communities in the physical world, whereas IT systems combined with the internet can be accessed in a more efficient system for exchanging and collecting such information from anywhere in the world. Based on previous research in information environment, consumers are looking for other opinion to manage the perceived risk that integrated in cognitively demanding task. The previous literature strongly support the influence of word of mouth and recommendation of customers in e-commerce setting (Smith, Satya. Menon, \& Sivakumar, 2005).

Reputation System: A reputation system collects, distributes and aggregates feedback about participants' past behavior. This system help people decide whom to trust, encourage trustworthy behavior and influence future buyers that may base their buying decision on the past history (Resnick et al., 2000) . Reputation systems are digitized word-of-mouth networks that allow individuals to rate, rank or provide feedback with regard to their online experiences for the benefit of others (Dellarocas, 2003; Josang, Roslan, \& Boyd, 2007). The basic principles of reputation systems are relatively easy to describe. Social Proof theory, predicts that individuals will look to the actions of others for cues (Fuller, et al., 2007). As more people are seen performing the actions (e.g. participating in eBay 's reputation system), or with the information from an authorized source (e.g., from BBBOnline.org), the credibility of the information increases (Kim, Sivasailam, \& Rao, 2004). Reputation system performance is based on two main concepts; reputation and trust (Jøsang, et al., 2007). In virtual environments that apply reputation systems, users can decide whether to trust an online merchant from the moment they establish reputation. Reputation systems provide an option to help users identify reliable relationships in the internet, allowing them to evaluate reputation of online seller. Sellers' honest behavior is greatly encouraged through reputation system and buyers' interest can be protected to some extent. On the other hand, buyers can collect more information from the reputation systems, which might facilitate their purchase behavior and make them more confident in online markets. The information available in reputation systems may be an effective mechanism in building consumer trust, and it is called as one of the trust - building technologies. There are a number of online reputation systems, which exist in Consumer-to-Consumer (C2C) such as ebay.com or Amazon.com. However, most of B2C and B2B sites do not provide users with feedback information. There are some centralized services though, which offer store ratings and reviews to their users, such as Bizrate.com or Resellerrating.com. One of the earliest and bestknown Internet reputation systems is run by eBay, which gather comments from buyers and sellers of each transaction. Reputations systems via feedback mechanisms have provided a new trust management style. It was indicated that the reputation system has had great influence on eBay's success (Fuller et al., 2007). On eBay for example, for each transaction, buyers and sellers can choose to rate each other by leaving feedback. Sellers with good records in reputation systems could easily bring themselves forward and to engage themselves in business. In eBay, feedback from buyers are categorized as positive (1), neutral (0), or negative $(-1)$ plus a short comment. The system aggregates the reviews of each user by summing all of his/her received ratings, and highlight the results on the user's profile page. In eBay, the feedback score is one of the most important information of a feedback profile. It's the number in parentheses next to a member's user ID. These ratings are used to determine feedback scores. 
Reputation System Challenges: Online reputation systems have become an important component of online shopping because they could help to elicit trust from buyers and ensure sellers' honesty to some extent (Dellarocas, 2003). Prior research fully embodies the positive effect of reputation system's importance in an online shopping web site, including building trust, increasing profit and making the whole process more efficient. However, little attention has been paid to the participation and effectiveness of these systems (Huang \& Hefu, 2009) . The article by Resnick et al. (2000) was an early study on reputation systems and their facilitating role in creating trust in e-commerce. The literature on the systems although is covered by many studies on emphasizing the role of them on e-commerce, but there are still a lot of things needed to be investigated in this area. The disembodied nature of online environments introduces several challenges related to the interpretation and use of online feedback. Some of these challenges have their roots in the subjective nature of feedback information. Although the existing literature has emphasized the importance of feedback and reputation in e-commerce transactions and creating trust, there are still some gaps in covering the deficiencies of current feedback system and improving the quality and effectiveness of feedbacks.

Acceptance of Feedbacks in Reputation Systems: One of the challenges in reputation systems which are the focus of this study is perceived trustworthiness of feedbacks of reputation systems, which simply means to what extent does it perceives the feedbacks as genuine, true and reliable. When people think of the incoming information as trustworthy, they will be more confident to adopt the feedbacks and use them for making purchase decision (Sussman \& Siegal, 2003a). The degree of consideration to which the users perceive the rating and feedback mechanism of the reputation systems as trustworthy will result in them accepting the feedbacks and use them in the online shopping decision-making. In general, reputation systems face challenges of developing immunization mechanisms against the actions of individual who make use of dishonest evaluation. In fact, one of the main problems for reputation systems is users who falsely improve the ratings by multiple faking identities. Users face some challenges in such feedback systems such as the anonymity of users in putting their feedback; they have to trust on feedback submitted by strangers, those who can easily give a rating that may not be fair or true to increase or decrease the reputation of each party. Although there are some studies conducted the trust models in e-commerce websites, there are still a few researches that focus on trust models for reputation. In a recent study by Vannoy (2008), the role of trust with intention to use feedbacks from reputation systems was examined via an empirical evaluation. In this study, a model with intention to use reputation systems feedbacks was proposed. The model recognized that trust in user feedback from reputation systems is a very different phenomenon.

Trust Transitivity and Reputation Systems: Reputation system's performance is based on two main concepts; reputation and trust (Jøsang et al., 2007). Reputation systems represent an option to help users identify reliable relationships in the internet, allowing them to evaluate reputation of online merchant through the experience of others. In virtual environments that apply reputation systems, users can decide whether to trust an online merchant based on the probable trust they have on provider of feedback. In reputation systems the trust transitivity is implicitly taken into account, based on Trust transitivity principle as illustrated in Figure1, when buyer 1 trusts buyer 2, and buyer 2 trusts the company, then buyer 1 derive a measure of trust in the company base on the trust on buyer 2 (Figure 1). However, trust transitivity is not as simple as it seems. For example, if Alice trusts Bob and Bob trusts Charlie, then Alice may trust Charlie as well, even though Alice does not know Charlie at all. If you ask why Alice trusts Charlie, she would say it is because she trusts Bob. The transitivity of trust is also known as a derived trust, means that trust is derived from an existing trust between agents.

Figure 1: Trust Transitivity Principle (Jøsang \& Pope, 2005)

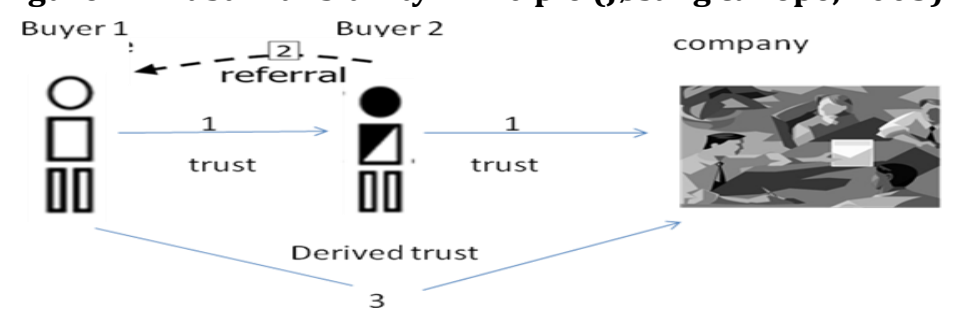


The level of trust through a transitive introduction may hold and is dependent on the strength of the original agent's trust relationship. Transitive trust in the area of reputation is a very important concept where users are identifying quality of services in online environment via a transitive introduction (Chang, Hussain, \& Dillon, 2005). Reputation is fuzzy in the sense that a transitive introduction is context and time dependent and the dependencies are not always explicit as there may be an inability to have the same view or understanding about the context and exact time frame in which the trust value or level was assigned (Chang, et al., 2005). Trustworthiness should also be capability-dependent. That is, the trustworthiness of one agent concerning car sales could be different from that of the same agent concerning car repair and this is mostly agreed (Jøsang \& Pope, 2005). The challenge in current reputation systems is that most receiver and provider of feedbacks in reputation systems are anonymous to each other (Bolton, Loebbecke, \& Ockenfels, 2008), therefore receiver of feedbacks has to make decision based on the idea of an unknown feedback provider who may submitted fake feedback, or even inaccurate feedback, as he may not be expert in sharing his idea. These characteristics in current reputation system create disturbance in trust transitivity process and put the validity and trustworthiness of feedbacks doubtful. Users who are seeking information on reputation of relevant e-sellers should take the risk to judge base on the feedbacks submitted by unknown people.

Social Relations and Reputation Systems: In most reputation systems, many techniques and algorithms are being used to reduce the degree of fake feedbacks. However there are a huge amount of information in the form of submitted feedbacks that are exchanged between provider and receiver of feedbacks who are strangers and except for the limited information based on their created ID and profile, no other cues is available for the degree of strength of tie and competency of these partners. The possible social relation between the receiver and provider of feedback, even if existed, is hidden from partners view. As the Figure 2 shows the consumer, who is looking for reputation information on an e-seller will use the feedbacks submitted by an agent who may be known or unknown to him.

Figure 2: Trustworthiness of feedback provider, adapted from (Chang, Dillon, \& Hussain, 2005)

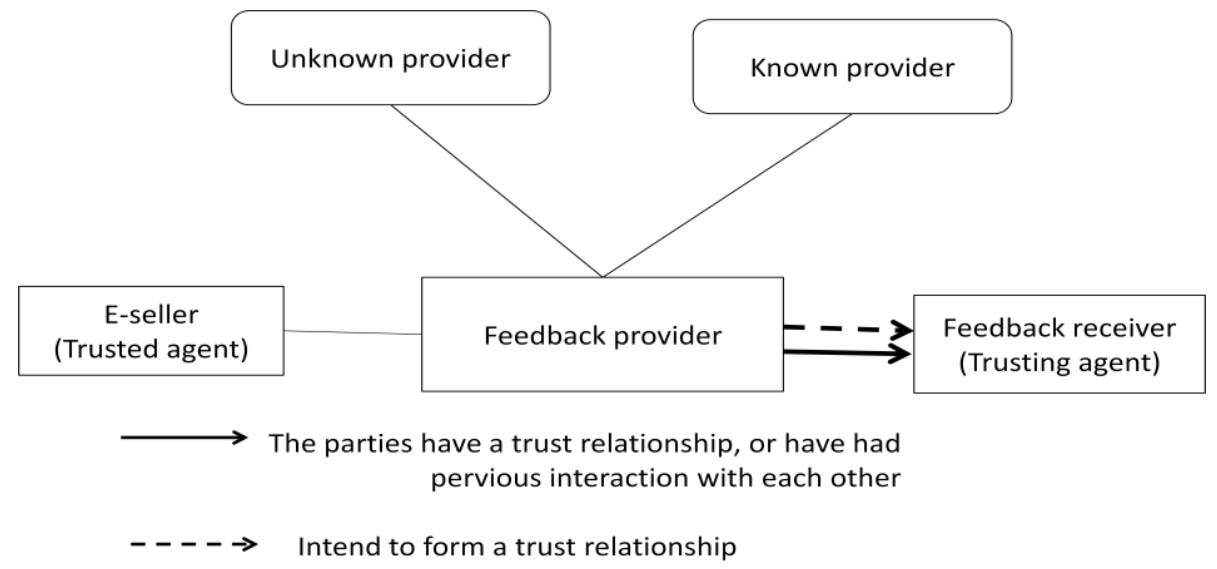

In Figure 2, we have two kinds of feedback provider: Unknown provider is an unknown agent who has no pervious connection and relation with trusting agent. Known provider is an agent who has had some social ties with receiver of feedback and has a form of homophily with him/her, e.g. friend, family, co-worker. The feedbacks can be weighted or assessed based on the value of feedback. Purchasing decisions are often strongly influenced by people whom the consumer knows and trusts. Naturally, when we want to buy an unfamiliar product, we often consult with our friends who have already used the product, since they are the ones that we can reach for immediate advice. When friends recommend product to us, we also tend to accept the recommendation because we believe their idea is trustworthy (Subramani \& Rajagopalan, 2003). Sina and Swearingen (2001) found that consumers are far more likely to believe recommendation from people they know and trust, i.e., friends and family members, rather than from automated systems in e-commerce websites. In reality a person 's decision to buy a product is often strongly influenced by his or her friends, acquaintances and business partners rather than strangers (Young Ae \& Jaideep, 2007). 
Identifying Relevant Factors Affecting Acceptance Of Feedbacks In Reputation Systems: Acceptance of feedbacks in reputation systems is critical to the success of the systems and significantly contributes to the effectiveness of submitted feedbacks in reputation to be used in the process of decision making. These acceptance factors are the precondition for a successful reputation system, as the failure to consider these factors on design and implementation of reputation system will not meet the expected results. Although many studies have been made on the reputation issue in online environment, this area is still in the primary stage of development and there is a need to study many aspects of reputation systems in moving toward optimized reputation systems that play their role effectively in the process of decision making for buying online.

\section{Proposed conceptual framework}

In this research on proposing a model for acceptance of feedbacks in reputation system, the goal is to associate a recipient with the sources that would provide the most acceptable and trustworthy information for making decision. The scope of research is critical in proposing our model, as there is no single theoretical framework that accounts for all the factors that are important for specified goal and problem of the research. Thus, it is necessary to consider the theoretical base for any complementary theories that can explain the acceptance of feedbacks in reputation system by assisting the data from social interaction in social networks to be utilized in reputation systems. In our case; to improve the effectiveness of reputation systems through features of social interactions in social networks, we can definitely benefit from social theories, as there is a large stream of literature that discuss the potential influence of relevant antecedents on the individuals evaluation and acceptance of advices. The acceptance of a source's advice construct has been studied in the areas of social psychology, marketing (with a special emphasis on word-of-mouth influence) (Brown, Broderick, \& Lee, 2007), and knowledge management (and specifically, knowledge sharing). Relevant theories appear; among others-in the works of Gilley (1998). Previous research indicated that people prefer to follow others rather than documents, when looking for information. Online Reputation information is often perceived as form of online word of mouth and such communication tends to flow via interpersonal channels based on shared interest and friendship. Figure 3 presents a view of our proposed model. In the section that follows, we explain the details of our model.

\section{Figure 3: A view of our proposed model on acceptance of feedbacks in reputation systems}

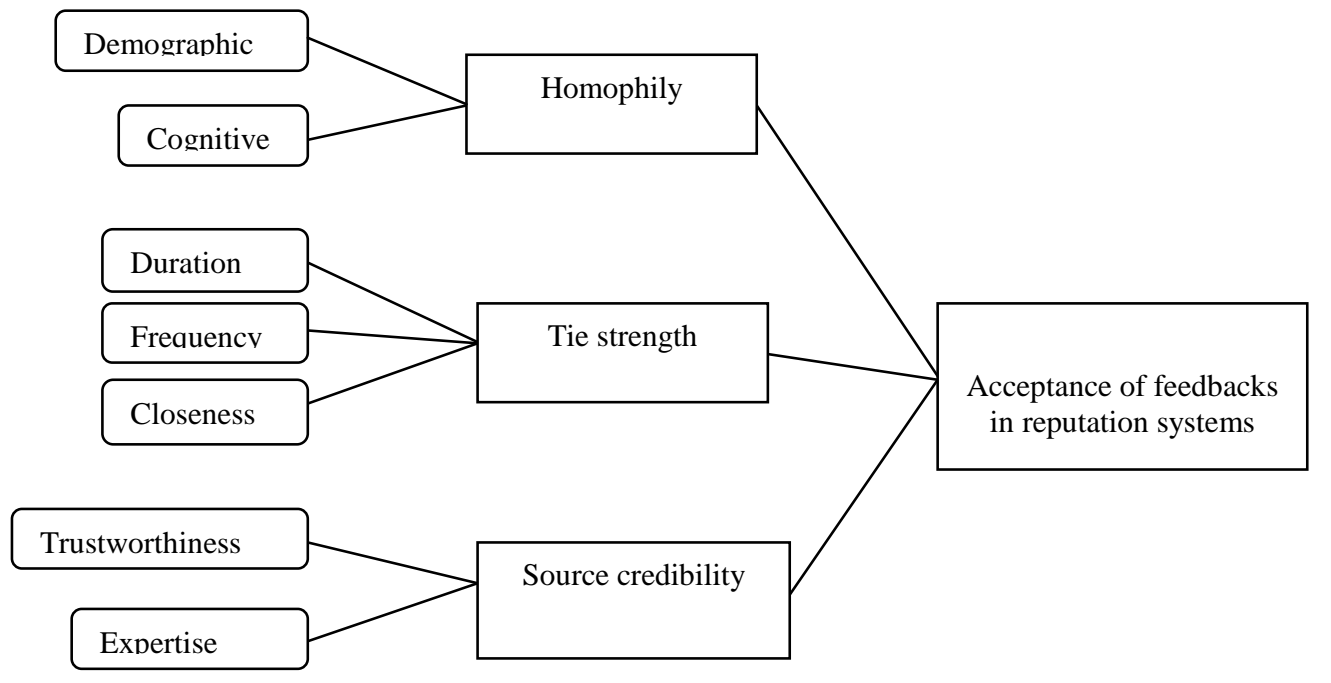

Proposed factors of feedback acceptance in reputation systems: Findings from related papers on acceptance of feedbacks and word of mouth in online environment need to be analyzed in order to produce the proposed factors and models. Factors of "acceptance of feedbacks in reputation system" refer to the factors that affect on the willingness of accepting a feedback, in reputation systems. The success of reputation system is significantly dependent on acceptance of submitted feedbacks in the systems that are used in the process of decision making in online buying. After comprehensive review and analysis on the factors that affect the acceptance of feedbacks in reputation systems in literature and previous work done on the subjects 
related to this issue, the proposed factors and the factors mentioned in previous works that are similar to our suggested factors or related to it in a part, is shown in Table 1. This shows that the proposed factors of our model are supported by the previous researches.

Table 1: Previous works related to acceptance of feedbacks in a reputation system.

\begin{tabular}{|c|c|c|c|}
\hline Construct & Related sources & Similar factor & Area of focus \\
\hline \multirow{7}{*}{ Homophily } & $\begin{array}{l}\text { (Luca, Luca, \& Cremonini, } \\
\text { 2011) }\end{array}$ & Similarity & trust in evolving social networks \\
\hline & $\begin{array}{l}\text { (Arazy, kumar, \& shapira, } \\
\text { 2010) }\end{array}$ & Homophily & $\begin{array}{l}\text { Framework for recommendation } \\
\text { system }\end{array}$ \\
\hline & (Bruyn \& Lilien, 2008) & Demographic similarity & Influence of word of mouth \\
\hline & (Lu, Zhao, \& Wang, 2008) & Perceived similarity & Trust in virtual community \\
\hline & (Brown, et al., 2007) & Homophily & Word of mouth in social networks \\
\hline & Bruyn \& Lilien, 2008) & Perceptual affinity & Influence of word of mouth \\
\hline & (Bruyn \& Lilien, 2008) & Tie strength & Word of mouth influence \\
\hline \multirow{6}{*}{$\underline{\text { Tie strength }}$} & $\begin{array}{l}\text { (Cruz, Motta, Santoro, \& Elia, } \\
\text { 2009) }\end{array}$ & Trust network & Reputation mechanism in communities \\
\hline & (Zhai \& Pan, 2008) & Members relationship & Social network based trust model \\
\hline & (Luca, et al., 2011) & Friend state & trust in evolving social networks \\
\hline & (Ugur \& Jennifer, 2007) & Path length & Trust in social networks \\
\hline & $\begin{array}{l}\text { (Maheswaran, Hon Cheong, \& } \\
\text { Ghunaim, 2007) }\end{array}$ & Strength of friendship & Trust model for social network \\
\hline & (Lu, et al., 2008) & familiarity & Trust in virtual community \\
\hline \multirow{10}{*}{$\begin{array}{l}\text { Source } \\
\text { credibility }\end{array}$} & (Arazy, et al., 2010) & Tie strength & Recommendation system \\
\hline & (Vannoy, et al., 2008) & $\begin{array}{l}\text { Trustworthiness of } \\
\text { reputation systems } \\
\text { feedbacks }\end{array}$ & $\begin{array}{l}\text { Trust and intention to use reputation } \\
\text { systems }\end{array}$ \\
\hline & $\begin{array}{l}\text { (Cheung, LUO, SIA, \& CHEN, } \\
\text { 2007a) }\end{array}$ & Source credibility & Evaluation of word of mouth \\
\hline & (Gutowska \& Sloane, 2009) & Credibility of referee & Evaluation of reputation metric \\
\hline & (Zhai \& Pan, 2008) & Trust degree of & Social network based trust \\
\hline & (Sinha, et al., 2001) & $\begin{array}{l}\text { recommendation nodes } \\
\text { Source of } \\
\text { recommendation }\end{array}$ & Recommendation by online systems \\
\hline & (Arazy, et al., 2010) & $\begin{array}{l}\text { Source perceived } \\
\text { trustworthiness }\end{array}$ & $\begin{array}{l}\text { Theory design for Recommendation } \\
\text { system }\end{array}$ \\
\hline & (Ling Liu 2012) & Source credibility & $\begin{array}{l}\text { Measurement on centralized } \\
\text { reputation systems }\end{array}$ \\
\hline & (Cho, Kwon, \& Park, 2009) & Expertise & Collaborative reputation system \\
\hline & (Bruyn \& Lilien, 2008) & Source expertise & Model of word of mouth influence \\
\hline
\end{tabular}

Identifying measures of acceptance of feedbacks in reputation systems: After proposing the factors affecting acceptance of feedbacks in reputation system and showing the supporting studies in pervious literature, in the next step we break down the factors into meaningful measures. The detailed measures associated with acceptance of feedbacks in reputation systems are collected and analyzed which resulted in a proposed list of detail measures for acceptance of feedbacks in reputation systems. In Table 2, the list of measures for each factor based on previous literature is presented. 
Table 2: Construct measurements based on previous studies

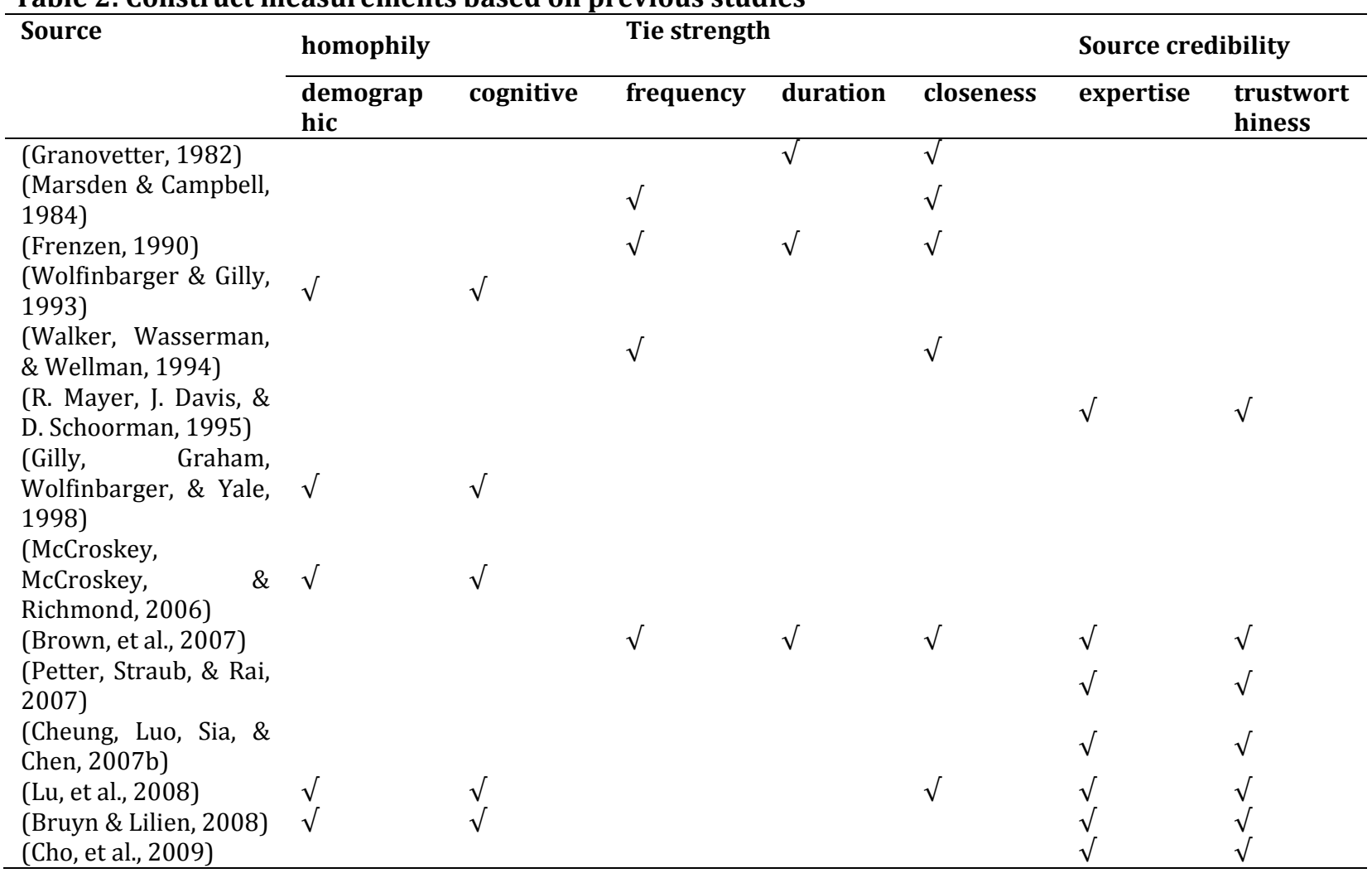

Tie strength: Tie strength which was first introduced by Granovetter (Granovetter, 1973) refers to strength of interpersonal ties. Interpersonal ties are defined as information-carrying connection between people and generally come into three varieties; strong, weak or absent. Tie strength is a multi-dimensional construct (Granovetter, 1973; Marsden \& Campbell, 1984; Money, et al., 1998) and it characterizes the closeness (i.e. emotional intensity) and time dimension (i.e. duration and frequency) of a relationship between parties. There are some arguments on the effectiveness of weak ties compare to strong tie on behavior of people in society as well as transmission of information in social networks. Tie strength has been found to be one of the most significant factors effecting the influence of word of mouth communications (Brown. J \& Reingen. P, 1987). Strength of ties may range from strong to weak based on frequency of interaction between parties, duration of interaction and intimacy. Previous studies showed that strong tie is effective on recipient's advice taking. Strong ties are featured by characteristics of a sense of intimate relationship, especially a voluntary tendency of investment in the relationship. There is also a frequent interaction in multiple contexts among parties, in which there is a sense of mutuality of relationship between partners (Walker, et al., 1994). Tie strength affect in interaction and information sharing among people, so that the frequency and level of information sharing among user with stronger tie is more compare to user with weak ties (Brown. J \& Reingen. P, 1987). Research on significance of weak ties on the other hand show that they are useful due to the novel information source they are (Granovetter, 1973). Research also revealed that they can be helpful in the flow of information(Granovetter, 1982; Rogers, 1995). Therefore, it seems that in a reputation system the range of information exchange among users who have had previous established relationship will be more compares to the exchange of information among unknown people. To measure strength of tie as an affecting factor on acceptance of feedbacks on a reputation system, we measure the duration of the relationship, the closeness and the interaction frequency between feedback provider and feedback receiver as an indicator of the relationship among them. Both these factors have been studied in the literature of advice taking, and these factors are conceptualized as dimensions of tie strength, as higher level construct in our proposed model. 


\section{Homophily}

Homophily refer to the similarities among individuals. It is a distinct form of tie strength, but it enables the formation of social ties (Brown. J \& Reingen. P, 1987). Homophily explains group cooperation in terms of the similarity of member's personality, including the extent individuals are similar in terms of attributes such as gender, education or life style, like or dislikes. The similarity of individuals influences them to having higher level of interpersonal interaction, trust and understanding compare to dissimilar individuals (Ruef, Aldrich, \& Carter, 2003). In previous studies on homophily the effect of it is established on acceptance of a source information (Bruyn \& Lilien, 2008; Money, et al., 1998). Homophily is a fundamental property of social networks. As in a social network, individuals are connected to each other base on some similar attributes with each other that lead to social relations in social networks. These similarities is called homophily and can be in different form of network ties such as marriage, friendship, work, advice and co-membership (McPherson, Smith-Lovin, \& Cook, 2001). The influence of accepting an individual's advice and idea created is through sharing of preferences, tastes and lifestyle among people(Brown, et al., 2007). Shared attitudes and similarities in demographic background have also shown to be an important factor that affect trustworthiness and interpersonal communication among people (Money, et al., 1998; Smith, et al., 2005). Homophily in reputation, systems can be existed between the people who submit the feedback and the person who is looking for reputation information and it can be measured based on various dimensions of this construct. In previous researches on homophily, there are divided into two categories which are called cognitive homophily (e.g preferences, attitudes, values) and demographic homophily (e.g. race, age)(McPherson, et al., 2001). In this research we propose utilizing the homophily effects among users in reputation systems, to be used for weighting the presented feedbacks for individuals needing them.

Source credibility: Source credibility is the believability of a source, as perceived by the recipient of the message (Hovland \& Weiss, 1951). Source refers to that individual who provides the seeker with information when asked. Based on source credibility theory source expertise and trustworthiness are elements that affect the credibility of an information source (Birnbaum \& Stegner, 1979; Buda, 2003). Source expertise, refers to the perceived competence of the source providing the correct information, and source trustworthiness is the degree to which a source is perceived to provide information that reflects the source's actual feeling or opinions (Eagly, 1993; Perloff, 1993). If a credible source tells the user that vender A is trustworthy, the user's trust in vender A is likely to increase. The higher the trustworthiness (is he honest?) and expertise (does he know what he is talking about?), a source is judged to have, the higher the importance given to information coming from that source (Hovland \& Weiss, 1951). Source credibility has been applied in commercial setting for evaluation of organizations and the judgment of web content, but little research has been done on its applicability in the subject of reputation systems in e-commerce. The social reputation system can present the information the user is looking for in reputation systems weighted based on credibility of feedback providers. In virtual environment, people perceived credibility of their peers could have a significant impact on the online decision making (Lim, Sia, Lee, \& Benbasat, 2006). If people think that the receiving information is credible, they possibility of adopting that information and using it for making purchase decision will be increased (Sussman \& Siegal, 2003b). In reputation systems the person who is looking for reputable information about an e-seller on a reputation system, will use it if he/she perceives the provided information by feedback as credible. He/she, if on the other hand, perceives it as less credible, the effect of the feedbacks will be reduced, and the reader is unlikely to follow the information provided in the reputation to avoid the potential risk. In current reputation systems as most feedbacks are submitted by strangers, there are rare cues on the credibility of those who submit their experience and idea on reputation systems, and the seeker of information is facing with numeral rating or textual messages that lack cues on credibility of feedback provider (Cheung, et al., 2007b). In this research, we will examine how source credibility affects the receiver of feedbacks.

Future Work: As future work, we validate our proposed model by investigating how proposed factors effect on acceptance of feedbacks in a reputation system. We employ a survey methodology to evaluate proposed model. A large-scale survey is going to be launched for evaluating the model constructs. This adopted the measures from existing instruments used in previous studies. The prerequisite for responding to questionnaire is having previous experience in shopping online and using reputation systems. A scenariobased approach will be used in our questionnaire. A scenario presupposes a setting where a system is used by 
an actor in his/her life. The behaviors and thinking of the actor, the appearance and behaviors of the system, and what interactions occur between them are described sequentially. The participants will be asked to imagine a scenario where they were planning to go to a restaurant and were looking for feedbacks on different restaurants. We adopt the methodology by (Marsden \& Campbell, 1984), and require participants to choose a friend from whom they would likely seek advice on restaurants. The questionnaire participants then rate the source of information on the measures that are included in the proposed research model. In this approach, analysis of collected data will be done by using Partial Least Squares (PLS). The PLS algorithm estimate path models using composite variables, sometime called latent variables, from a number of indicator items, called manifest variables.

\section{Conclusion}

The primary objective of this paper is in proposing a new approach of utilizing social relations in supporting reputation systems. Trust transitivity is the base of reputation systems in sharing feedbacks by some individuals who have had experience in interaction with an e-seller or buying a product or service online, thus the persons who are looking for reputation information on an e-seller or product will trust the feedbacks submitted and use them for their decision making in online shopping. This paper showed that with some condition for transitivity of trust such as the capability of recommender or the strength of trust relationship of the agent are important conditions of trust transitivity. In reputation systems as most individuals who are involved are anonymous to each other and there is very limited information on their attributes it is difficult to distinguish some cues that is necessary for transitivity of trust. This research proposes a model for accepting feedbacks in reputation systems, which includes three factors known as homophily, tie strength and source credibility as factors that influence on acceptance of feedbacks in reputation systems. These attributes can be extracted from social relations of users and be used as some cues to help the process of trust transitivity conducted effectively. For filtering the presented feedbacks in reputation systems based on these three factors, the reputation systems can gather the necessary information on homophily, tie strength and source credibility of involved partners from online social networks. Currently different types of data on people's social relation and interaction is available online via social networks that potentially can be a very good source of information to support reputation systems and leading us toward having social reputation systems. The integration of social networks with reputation systems will also improve the performance of current reputation system in terms of the accuracy and trustworthiness of submitted and exchanged information in reputation systems. The attribute of users social relationship in getting the necessary information to filter and weight the submitted feedbacks in reputation systems are based on the social relationship of users and use them to get information on homophily, tie strength and source credibility of feedback providers to improve the acceptance of feedbacks in reputation systems.

\section{References}

Arazy, O., kumar, N. \& shapira, B. (2010). a theory of driven design framework for social recommendation systems. journal of the associaltion for information systems, 11(9).

Ba, S. \& Pavlou, P. A. (2002). Evidence of the Effect of Trust Building Technology in Electronic Markets: Price Premiums and Buyer Behavior. MIS Quarterly, 26(3), 243-268.

Birnbaum, M. H. \& Stegner, S. E. (1979). Source Credibility in Social Judgment: Bias, Expertise, and the Judge's Point of View. Journal of Personality and Social Psychology, 37(48-74).

Bolton, G., Loebbecke, C. \& Ockenfels, A. ( 2008). How Social Reputation Networks Interact with Competition in Anonymous Online Trading: An Experimental Study. CESifo Working Paper Series No. 2270. Available at SSRN: http://ssrn.com/abstract=1114755

Brown, J., Broderick, A. J. \& Lee, N. (2007). Word of mouth communication within online communities: conceptualizing the online Social network. Journal of Interactive Marketing, 21(3).

Brown, J. \& Reingen, P. (1987). Social Ties and Word- of-Mouth Referral Behavior. Journal of Consumer Research in Consumer Behaviour, 14(350-62).

Bruyn, A. D. \& Lilien, G. L. (2008). A multi-stage model of word-of-mouth influence through viral marketing. Intern. J. of Research in Marketing, 25, 151-163.

Buda, R. (2003). he Interactive Effect of Message Framing, Presentation Order, and Source Credibility on Recruitment Practices. International Journal of Management, 20(156-163). 
Chang, E. J., Hussain , F. K. \& Dillon, T. S. (2005). Fuzzy Nature of Trust and Dynamic Trust Modelling in Service Oriented Environments. Paper presented at the ACM, SWS'05, Fairfax.

Chang., E., Dillon., T. \& Hussain, F. K. (2005). Trust and reputation for service -oriented environments: WILEY.

Cheung, M. Y., LUO, C., SIA, C. L. \& Chen, H. (2007a). How do People Evaluate Electronic Word-Of-Mouth? Informational and Normative Based Determinants of Perceived Credibility of Online Consumer Recommendations in China. Paper presented at the PACIS 2007 Proceedings

Cheung, M. Y., Luo, C., Sia, C. L. \& Chen, H. (2007b). How do people evaluate electronic Word-of-Mouth? Informational and normative based determinants of perceived credibility of online consumer recommendations in China.

Cho, J., Kwon, K. \& Park, Y. (2009). Q-rater: A collaborative reputation system based on source credibility theory. Expert Systems with Applications, 36(2, Part 2), 3751-3760.

Cruz, C. C. P., Motta, C. L. R., Santoro, F. M. \& Elia, M. (2009). Applying Reputation Mechanisms in Communities of Practice: A Case Study. Journal of Universal Computer Science, 15(9).

Dellarocas, C. (2003). The Digitization of Word of Mouth: Promise and Challenges of Online Feedback Mechanisms. Management Science, 49(10), 1407-1424.

Eagly, A. H. (1993). The Psychology of Attitudes. Fort Worth, TX: Harcourt Brace Jovanovich.

Frenzen, J. K. (1990). Purchasing behavior in embedded markets. 17, 1(12).

Fuller, M., Serva, M. \& Benamati, J. (2007). Seeing Is Believing: The Transitory Influence of Reputation Information on E-Commerce Trust and Decision Making. Decision Sciences, 38(4), 675-699.

Gilly, M. C., Graham, J. L., Wolfinbarger, M. F. \& Yale, L. J. (1998). A dyadic study of interpersonal information search. Journal of the Academy of Marketing Science, 26(2), 83-100.

Granovetter, M. (1973). The strenght of weak ties. American journal of sociology, 78(6).

Granovetter, M. (1982). The Strength of Weak Ties: A Network Theory Revisited. Social Structure and Network Analysis, Beverly Hills, CA: Sage, 105-130.

Gregg, D. G. \& Scott, J. E. (2006). The Role of Reputation Systems in Reducing On-Line Auction Fraud. International Journal of Electronic Commerce, 10(3), 95-120.

Gutowska, A. \& Sloane, A. (2009). Evaluation Of Reputation Metric For The B2c E-Commerce Reputation System. Paper presented at the WEBIST 2009 - 5th International Conference on Web Information Systems and Technologies.

Gutowska, A. \& Sloane, A. (2010). Modelling the B2C Marketplace: Evaluation of a Reputation Metric for eCommerce. Paper presented at the WEBIST 2009

Hovland, C. \& Weiss, W. (1951). The Influence of Source Credibility on Communication Effectiveness. Public Opinion Quarterly, 15(4), 635-650.

Huang, Q. R., Davison, Y. \& Hefu, L. (2009). An Exploratory Study on Buyers' Participation in Reputation Systems. Paper presented at the Pacific Asia Conference on Information Systems (PACIS).

Jøsang, A., Ismail, R. \& Boyd, C. (2007). A survey of trust and reputation systems for online service provision. decision support systems, 43(2), 618-644.

Jøsang, A. \& Pope, S. (2005). Semantic Constraints for Trust Transitivity. Paper presented at the Second AsiaPacific Conference on Conceptual Modelling (APCCM2005).

Josang, A., Roslan, I. \& Boyd, C. (2007). A Survey of Trust and Reputation Systems for Online Service Provision. . Decision Support Systems, 43(2), 618-644.

Kim, D. j., Sivasailam, N. \& Rao, H. R. (2004). information insurance in B2C websites for information goods/services. electronic markets, 14(4), 344-359.

Komiak, S. (2010). The Effects of Perceived Information Quality and Perceived System Quality on Trust and Adoption of Online Reputation Systems. Paper presented at the AMCIS 2010 Proceedings.

Li, D., Browne, G. J. \& Chau, P. Y. K. (2006). An Empirical Investigation of Web Site Use Using a CommitmentBased Model. Decision Sciences, 37(427-444).

Lim, K. H., Sia, C. L., Lee, M. K. O. \& Benbasat, I. (2006). How Do I Trust You Online, and If So, Will I Buy?: An Empirical Study of Two Trust Building Strategies. Journal of Management Information Systems, 23(2), 233-266.

Ling-Liu, M. M. (2012). Systematic analysis of centralized online reputation systems. Decision Support Systems.

Lu, Y., Zhao, L. \& Wang, B. (2008). From virtual community members to C2C e-commerce buyers: Trust in virtual communities and its effect on consumers' purchase intention. Electronic Commerce Research and Applications, In Press, Corrected Proof. 
Luca, A., Luca, C. \& Cremonini, M. (2011). Modifying Trust Dynamics through Cooperation and Defection in Evolving Social Networks. In Proceedings of the 4th International Conference on Trust and Trustworthy Computing (TRUST 2011), 6740, 131-145,.

Maheswaran, M., Hon-Cheong, T. \& Ghunaim, A. (2007). Towards a Gravity-Based Trust Model for Social Networking Systems. Paper presented at the Distributed Computing Systems Workshops, 2007. ICDCSW '07. 27th International Conference on.

Marsden, P. \& Campbell, K. (1984). Measuring Tie Strength. Social Forces, 63(2), 482-501.

Mayer, D. \& Schoorman, E. (1995). An Integrative Model of Organizational Trust. Academy of Management Review, 20(3), 709-734.

Mayer, R., Davis, J. \& Schoorman, D. (1995). An Integrative Model of Organizational Trust. The Academy of Management Review, 20(3), 709-734.

McCroskey, L. L., McCroskey, J. C. \& Richmond, V. P. (2006). Analysis and improvement of the measurement of interpersonal attraction and homophily. Communication Quarterly, 54(1-31).

McDonald, C. G. \& Slawson-Jr., V. (2002). Reputation in an Internet Auction Market. Economic inquiry, 40(633650).

McPherson, M., Smith-Lovin, L. \& Cook, J. M. (2001). Birds of a feather:Homophily in social networks. Annual Review of Sociology, 27, 415-444.

Money, R. B., Gilly, M. C. \& Graham, J. L. (1998). Explorations of National Culture and Word-of Mouth Referral Behavior in the Purchase of Industrial Services in the United States and Japan. Journal of Marketing, 62, 76-87.

Perloff, R. M. (1993). The Dynamics of Persuasion. Lawrence, NJ: Erlbaum Associates.

Petter, S., Straub, D. \& Rai, A. (2007). Specifying Formative Constructs In Information Systems Research1. MIS Quarterly, 31(4).

Resnick, P., Zeckhauser, R., Friedman, E. \& Kuwabara, K. (2000). Reputation Systems: Facilitating Trust in Internet Interactions.

Rogers, E. (Ed.). (1995). Diffusion of Innovations (4th Ed).

Ruef, M., Aldrich, H. E. \& Carter, N. M. (2003). The Structure of Founding Teams: Homophily, Strong Ties and Isolation Among U.S. Entrepreneurs. American Sociological Review, 68(195-222).

Sinha, R., Sinha, R. \& Swearingen, K. (2001). Comparing Recommendations Made by Online Systems and Friend. Paper presented at the In Proceedings of the DELOS-NSF Workshop on Personalization and Recommender Systems in Digital Libraries

Smith, S. M. \& Sivakumar, K. (2005). Online peer and editorial recommendations, trust, and choice in virtual markets. Journal Of Interactive Marketing, 19(3).

Subramani, M. R. \& Rajagopalan, B. (2003). knowledge-sharing and influence in online social networks via viral marketing. communication of the ACM, 46(12), 300-307.

Sussman, S. W. \& Siegal, W. S. (2003a). Informational Influence in Organizations: An Integrated Approach to Knowledge Adoption. Info. Sys. Research, 14(1), 47-65.

Sussman, S. W. \& Siegal, W. S. (2003b). Informational Influence in Organizations: An Integrated Approach to Knowledge Adoption. Information Systems Research, 14(1), 47-65.

Ugur, K. \& Jennifer, G. (2007). Sunny: a new algorithm for trust inference in social networks using probabilistic confidence models. Paper presented at the Proceedings of the 22nd national conference on Artificial intelligence, 2.

Vannoy, S. A., Nath, A. K. \& Iyer, L. (2008). The Role of Trust in the Intention to Use Feedback from Reputation Systems. Paper presented at the AMCIS 2008 Proceedings.

Walker, J., Wasserman, S. \& Wellman, B. (1994). Statistical Models for Social Support Networks. In Advances in Social Network Analysis (Eds.). Thousand Oaks, CA: Sage.

Wolfinbarger, M. F. \& Gilly, M. C. (1993). The encoding and decoding of gift symbolism. Working paper : University of California at Irvine.

Young-Ae, K. \& Jaideep, S. (2007). Impact of social influence in e-commerce decision making. Paper presented at the Proceedings of the ninth international conference on Electronic commerce.

Zhai, D. \& Pan, H. (2008). A Social Network-Based Trust Model for E-Commerce. Paper presented at the Wireless Communications, Networking and Mobile Computing, 2008. WiCOM '08. 4th International Conference on.

Zucker, L. G. (1986). Production of trust: Institutional sources of economic structure. Research in Organizational Behavior, 8(2). 